\title{
LOS MASCARONES DEL GRUPO 6C-XVI DE TIKAL: ANÁLISIS ICONOGRÁFICO PARA EL CLÁSICO TEMPRANO
}

\author{
Juan Antonio VALDÉs \\ Universidad de San Carlos, Guatemala
}

Durante los últimos meses de 1981 tuve a mi cargo el inicio de los trabajos exploratorios del sector habitacional al sur del grupo mayor conocido como Mundo Perdido de Tikal. En esta oportunidad fueron investigados cinco grupos habitacionales, presentando cada uno de ellos diferencias arquitectónicas de la última época constructiva correspondiente al Clásico Tardío, quedando enmarcados dentro de los planes de plaza 2 y 3 asignados para Tikal (Becker, 1982; Valdés, 1983). Posteriormente los estudios de patrón de asentamiento fueron ampliados por otros miembros del Proyecto Nacional Tikal, investigándose un total de 16 grupos (Valdés, 1985: 49-65) localizados en los Cuadrantes Perdido y Corriental.

El grupo más pequeño de los conjuntos seleccionados para investigación fue el denominado 6C-XVI, en donde eran observables únicamente tres estructuras de pequeñas dimensiones y que en el plano de Tikal (Carr y Hazard, 1961) se conocen como $6 \mathrm{C}-51,52$ y 53 (fig 1 ). Anteriormente a nuestra investigación, este pequeño conjunto había sido muestreado por medio de pozos de sondeo ejecutados por miembros de la Universidad de Pennsylvania, asignándose un fechamiento correspondiente al Clásico Tardío.

Uno de nuestros principales objetivos en 1981 para el Grupo 6C-XVI era confirmar el fechamiento obtenido por Pennsylvania, para así poderlo relacionar de manera temporal y espacial con los otros conjuntos que se estaban excavando en su cercanía. Debido a esto, fueron realizados varios pozos de muestreo directamente en plaza, los que produjeron cerámica que permitió confirmar su fechamiento para el Clásico Tardío. 


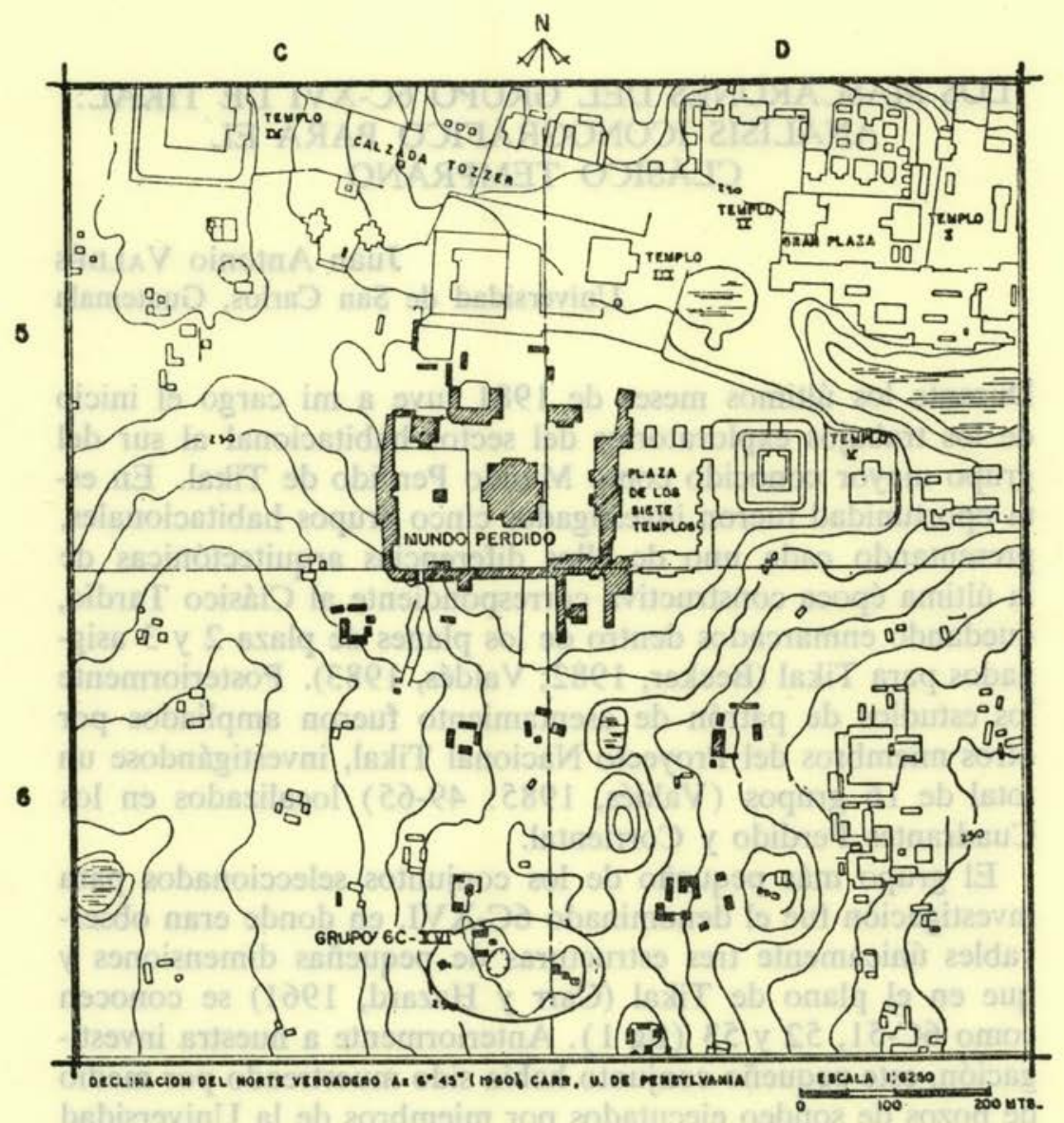

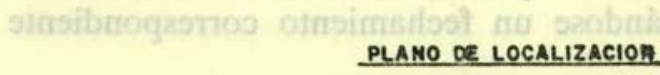

MUNDO PERDIDO $Y$ GRUPO $6 C-X V I$

Figura 1. 
Esta cerámica, sin embargo, estaba muy cerca de la superficie y bastante erosionada, por lo que se decidió realizar dos pozos más en las afueras del grupo para estar completamente seguros del fechamiento, considerándose que con ello se daría cumplimiento a la investigación y así la misma quedaba concluida.

Para nuestra sorpresa, esto no fue así, ya que fueron estos dos últimos pozos los que aportaron datos de reveladores rasgos importantes que obligaron a ampliar las excavaciones al descubrirse la presencia de diferentes estructuras más antiguas en los niveles inferiores. La importancia de este lugar resultó ser mucho mayor de lo que se pensó en un principio, lo cual conllevó un arduo trabajo por medio del sistema de túneles durante dos años y medio para conocer completamente la complejidad arquitectónica de varias plazas y edificios, así como también de mascarones, murales polícromos, tumbas y un marcador de juego de pelota esculpido (Laporte y Fialko, 1985; 1987).

Debajo de la ocupación habitacional del Clásico Tardío, se descubrieron edificios que forman una larga secuencia de 23 estadios constructivos pertenecientes al Clásico Temprano y específicamente fechados para las fases Manik 2 y Manik 3, o sea entre los años 300 y 550 d.C. (Laporte, 1987). Una serie de mascarones estucados asociados con arquitectura fueron descubiertos en tres edificios conocidos como Sub-4, Sub-73 y Sub75 ; el primero de ellos fechado para la parte tardía de Manik 2, mientras que los otros dos corresponden a la faceta Manik 3-B y son estos mascarones los que forman el sujeto principal de este trabajo, los que serán presentados a continuación.

Mascarones Manik 2 Tardío Y 3-A: 350-488 d.C.

\section{Edificio Sub-4}

El edificio Sub-4 se localiza formando el límite sur de la plazoleta sur del grupo 6C-XVI (fig. 2). Fue construido desde el primer estadio del conjunto y utilizado hasta el estadio 10, por lo que se conoce que estuvo en funciones durante la parte terminal de Manik 2 y en Manik 3-A (350-488 d.C.). "Consiste en una plataforma en la cual se aplicó el modo talud-tablero en los sectores laterales, sin considerar el frente para ello, en forma combinada con molduras en faldón y entrecalles a dis- 


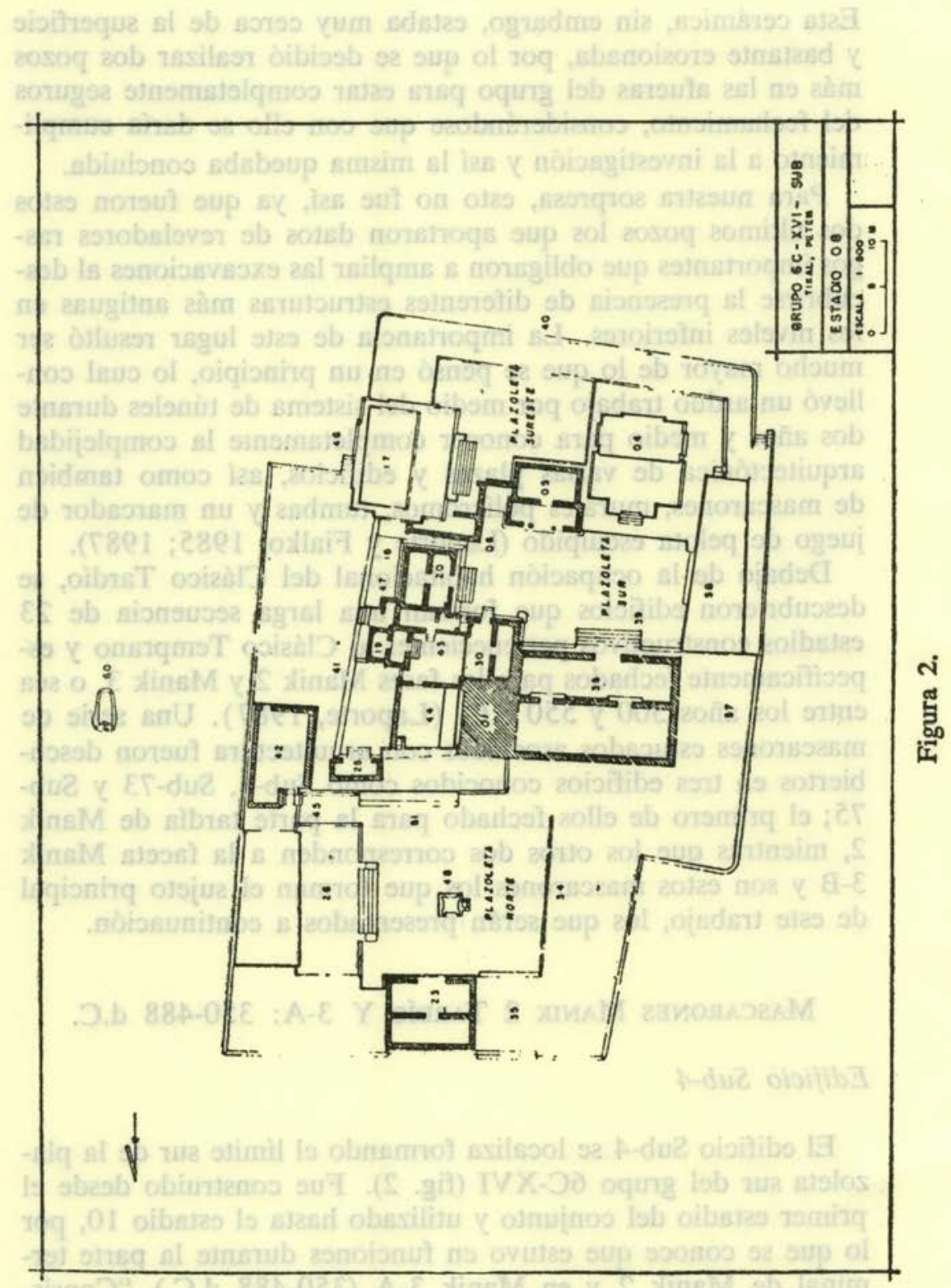


tintas alturas, lográndose así un efecto especial que marcará el estilo a seguir por otras edificaciones" (Laporte, 1985: 17).

$\mathrm{El}$ edificio se encuentra orientado hacia el norte (fig. 3), en donde presenta una escalinata exenta, la cual estuvo desde el primer momento flanqueada por un mascarón a cada lado de ella. Durante el proceso de excavación únicamente pudo conocerse el mascarón ubicado al este de la escalinata, ya que el sector oeste del edificio fue destruido por los constructores mayas, al efectuarse remodelaciones en el lugar. Junto al mascarón existente fueron descubiertos los restos de una pintura que muestra luna figura humana de perfil, pintada en colores rojo y naranja, de la que pocos trazos persisten.

El mascarón encontrado mide $2.20 \mathrm{~m}$ de largo (figs. 4 y 5), y su altura total se desconoce por encontrarse mutilada la sección superior. Está elaborado en piedra recubierta de estuco y pintado de color rojo. La figura está compuesta de una cabeza grotesca en la parte inferior, de la que emerge otra creatura con rasgos antropomorfos y llevando cada una de ellas su respectivo arreglo de orejeras, volutas en forma de $\mathrm{J}$, y un gran tocado de plumas que descienden de la figura superior enmarcando todo el conjunto.

El mascarón inferior está bien preservado y muestra junto a la cabeza varias volutas que salen hacia ambos lados de ella, lleva grandes ojos en forma rectangular, nariz felina y labio superior pronunciados (fig. 5), y en la boca presenta una voluta bifurcada hacia los extremos. Todo lo anterior se encuentra sostenido por tres figuras redondeadas, que presentan al mismo tiempo otros círculos en su interior y que parecen ser gotas de sangre, estando todo el conjunto pintado de color rojo. Lo anterior hace que dicha creatura pueda ser interpretada como el jaguar-sol del inframundo, del cual emerge la cabeza de otra figura, en este caso con rasgos humanos portando volutas en las mejillas y gotas de sangre (?) junto a los labios y hacia abajo de la boca. La cara humana está destruida arriba de la región de la boca, por lo que es imposible conocer sus características diagnósticas. Sin embargo, es factible observar parte de las grandes orejeras que lo acompañan, así como también el arreglo de plumas que descienden de la parte superior, lo cual indica su posición predominante en el contexto cosmogónico, y que puede identificarse como la deidad solar en su aspecto de cielo. 


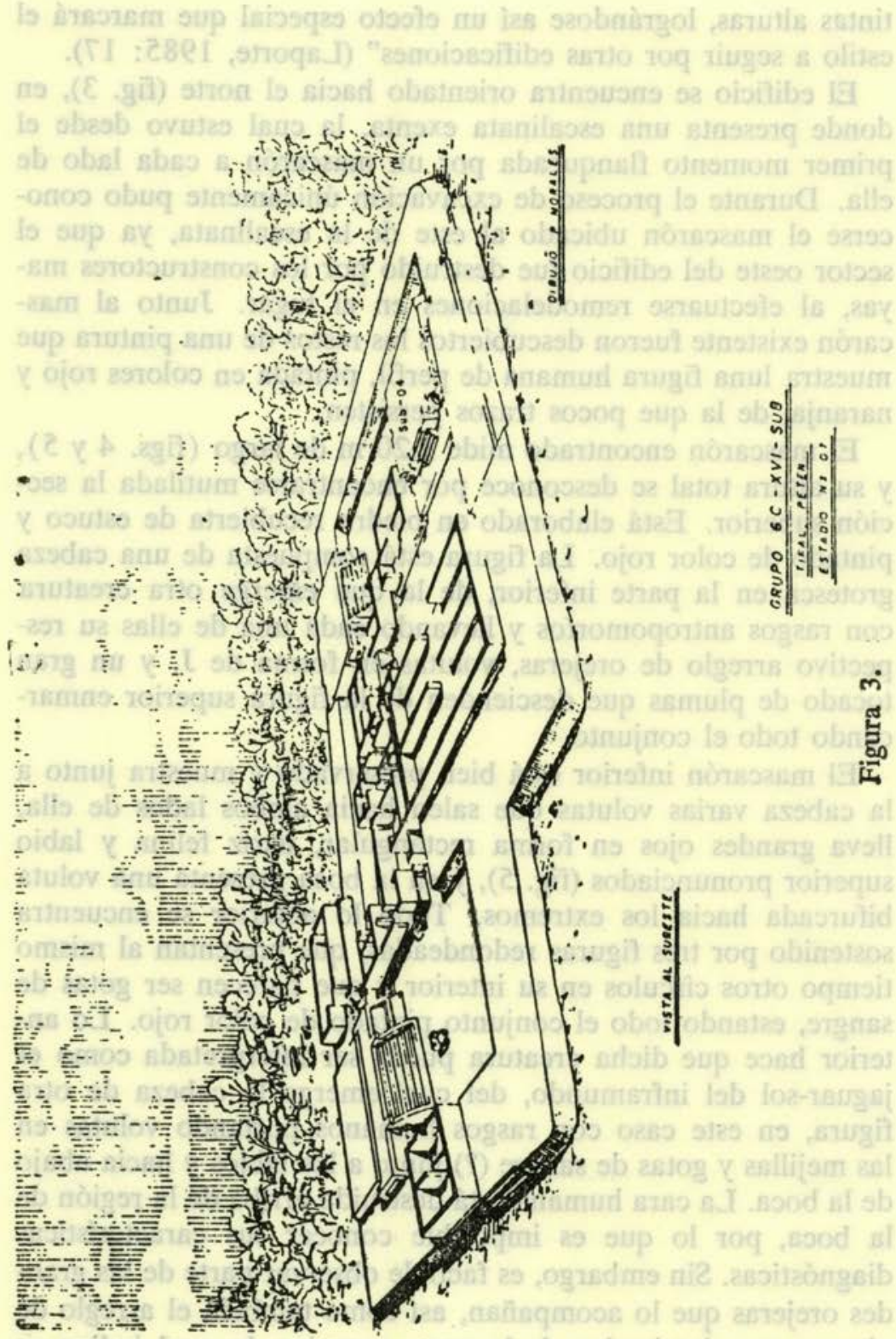




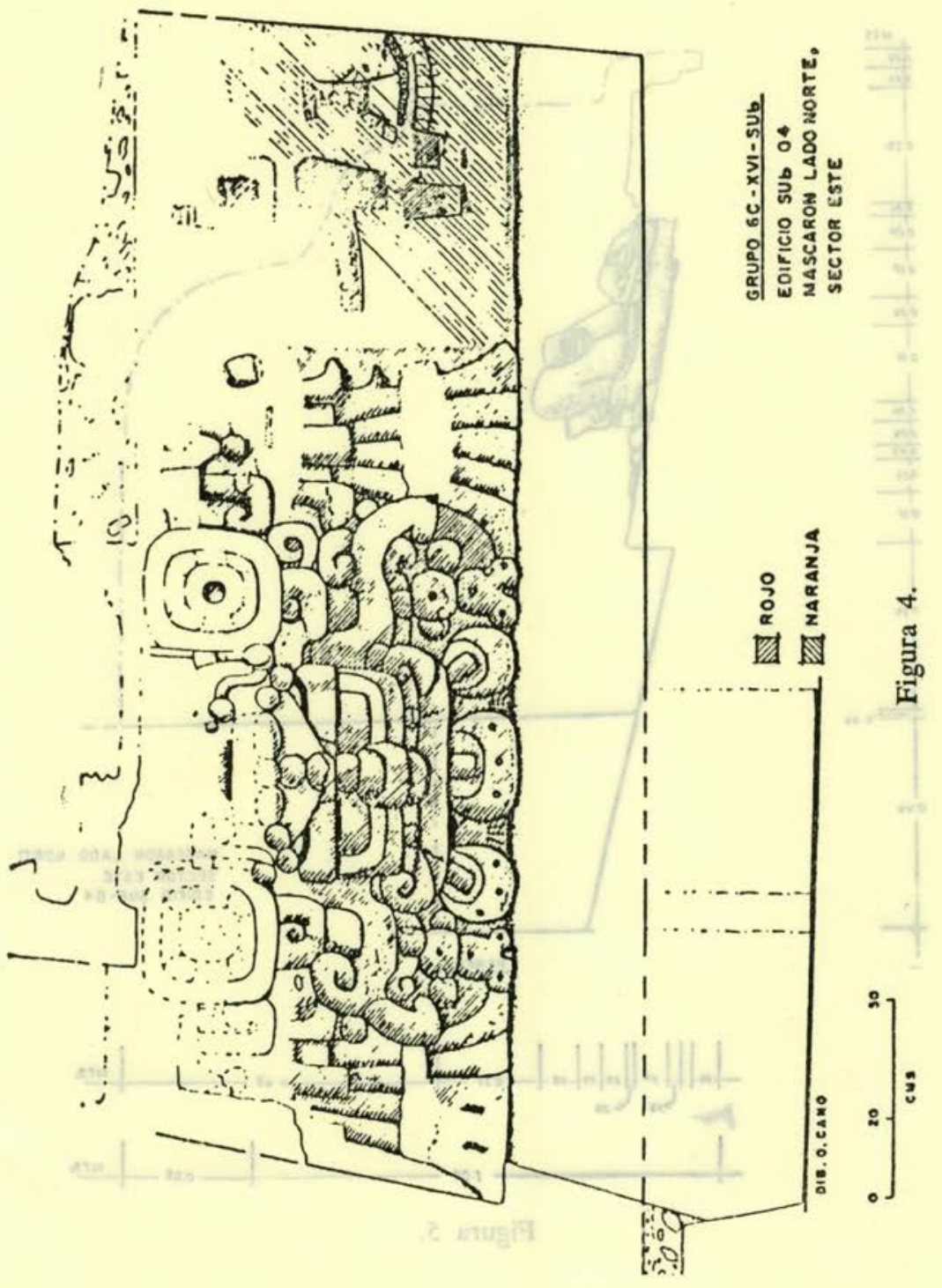




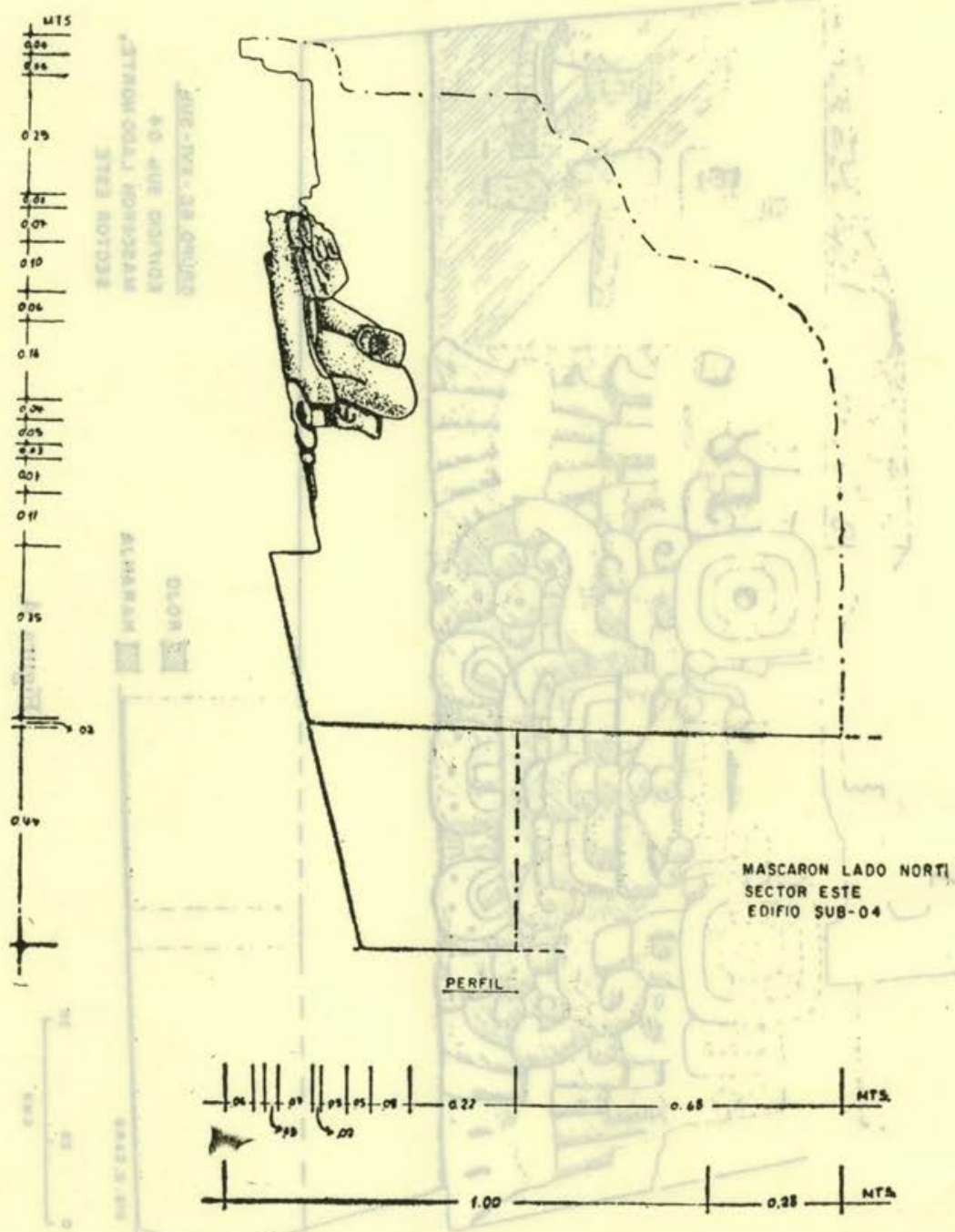

Figura 5 . 
Por su posición al este del edificio, es seguro que se trata de la figura del sol naciente por la mañana, el cual emerge del sol esquelético de la noche o del inframundo. El lado oeste de la plataforma Sub-4 debió tener por lo tanto otra deidad solar, que portara elementos que representaran el sol en el ocaso, cumpliendo con ello el proceso dual de la estrella mayor del universo, ejemplos que han sido plenamente identificados en otros sitios del área maya desde los tiempos preclásicos.

En el caso concreto en que se representaron figuras emergiendo de otra figura inferior, sus orígenes se remontan al Preclásico Tardío, como se observa en los mascarones de la pirámide 29-B de Cerros (fig. 6) en donde se muestra un jaguar esquelético de labio pronunciado y una gran voluta bifurcada en la boca. De la parte superior de este jaguar sale otra figura de menores proporciones, en este caso con forma humana y portando volutas en la boca. Todo el conjunto ha sido interpretado por Freidel (1982) como el nacimiento del sol saliendo del inframundo, e indica además que ésta puede ser una versión preclásica de las figuras antropomorfas de G-III de la Tríada de Palenque mostradas durante el periodo Clásico.

Como sabemos, esta tradición que ligó escultura con arquitectura vio sus inicios en las tierras bajas durante el Preclásico Tardío y muchos de los elementos iconográficos continuaron siendo utilizados posteriormente en los mascarones, estelas y altares del periodo Clásico.

Un ejemplo de ello se localizó en la Acrópolis Norte de Tikal (Miller, 1986) en donde se encuentra el edificio 5D-23-2o. fechado para el Clásico Temprano y también decorado con mascarones que muestran similitud con el edificio 29-B de Cerros y Sub-4 del Grupo 6C-XVI de Tikal. En el mascarón del edificio de la Acrópolis Norte (fig. 7) se observa también un ser antropomorfo representando la soberanía, emergiendo de la cabeza de una figura felina identificada como el juguar-sol del inframundo, que porta el símbolo real de petate y las volutas saliendo de su boca y de la parte superior de los ojos.

Como puede observarse en los tres mascarones discutidos sobre los edificios de Cerros y Tikal, las representaciones del sol diurno emergiendo del jaguar-sol nocturno o del inframundo, se presentan en el área maya durante el Preclásico Tardío y Clásico Temprano; imágenes que eran claramente visibles y que 


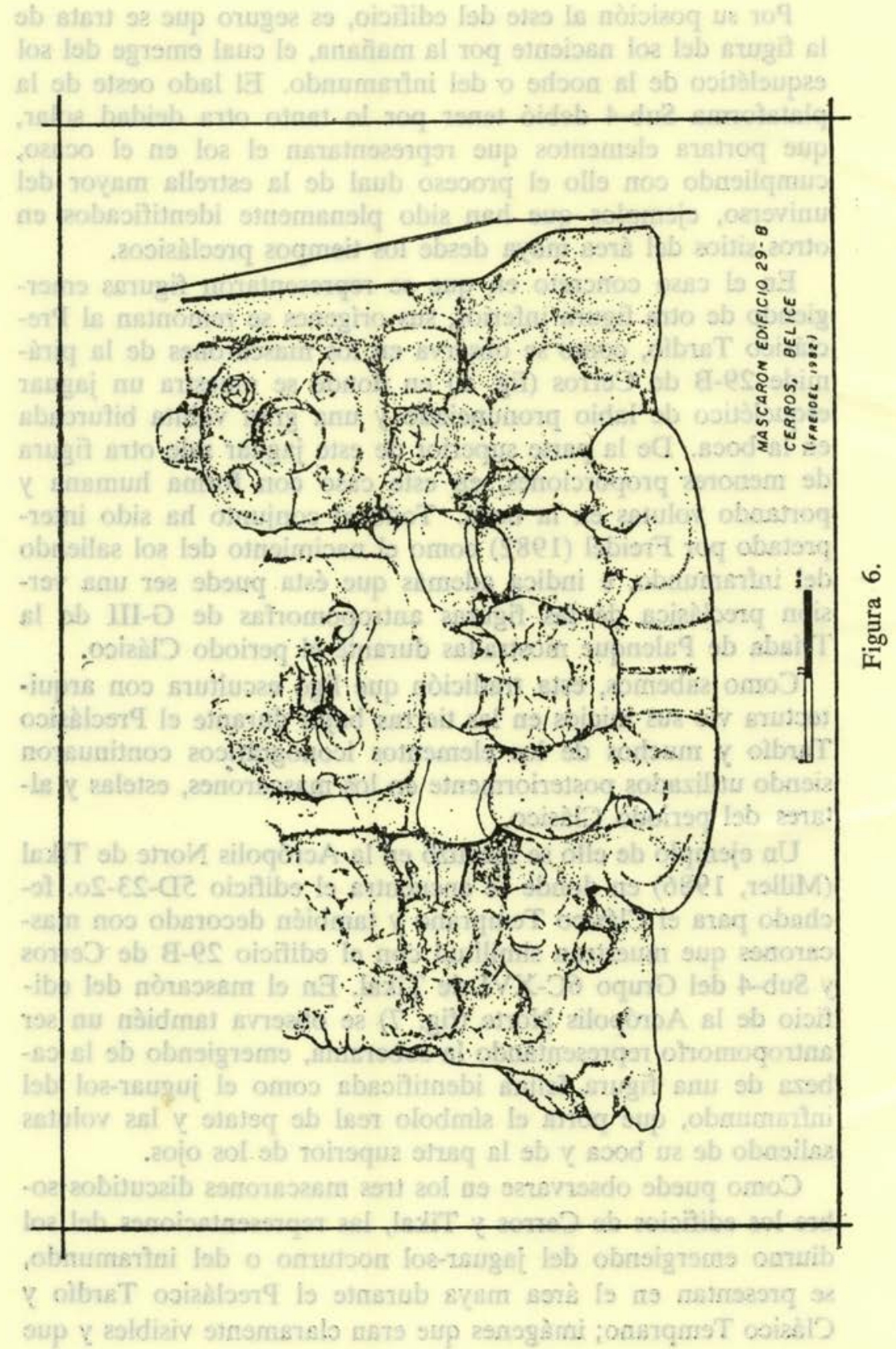




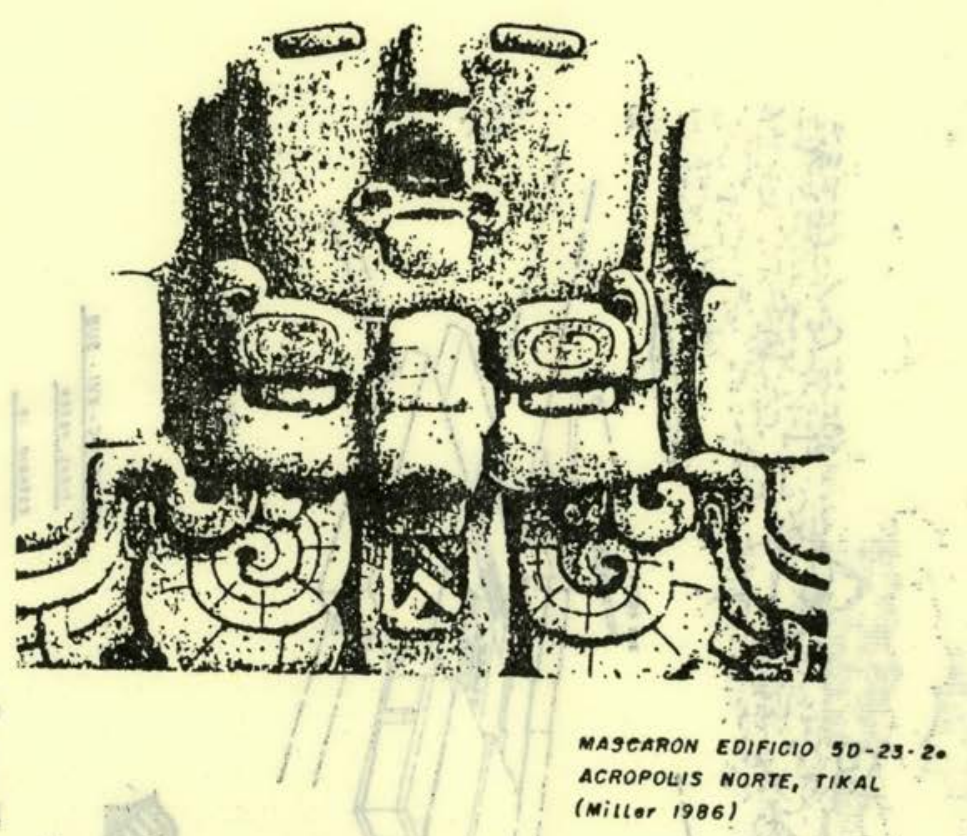

Figura 7.

mostraban una alegoría que evocaba un mensaje de la vida cotidiana. Esto debió ser fácilmente entendible por el pueblo maya, motivo que fue al mismo tiempo aprovechado para concretar la relación existente entre dioses y gobernantes para remarcar y demostrar a toda la población el origen divinizado de los dirigentes, los que en muchos casos se muestran naciendo o tomando el poder del dios sol, una de las deidades más respetada y más poderosa de la civilización maya. Con ello, los gobernantes adquirieron la fuerza, el poder y la divinización necesaria para llevar a cabo sus funciones administrativas y gubernamentales. En las representaciones de este tipo, "las imágenes centrales de jaguar sugieren la dicotomía primaria del sol como deidad de la tierra y el cielo; mientras que la máscara superior representa el aspecto cielo" (Freidel, 1982: 219). 


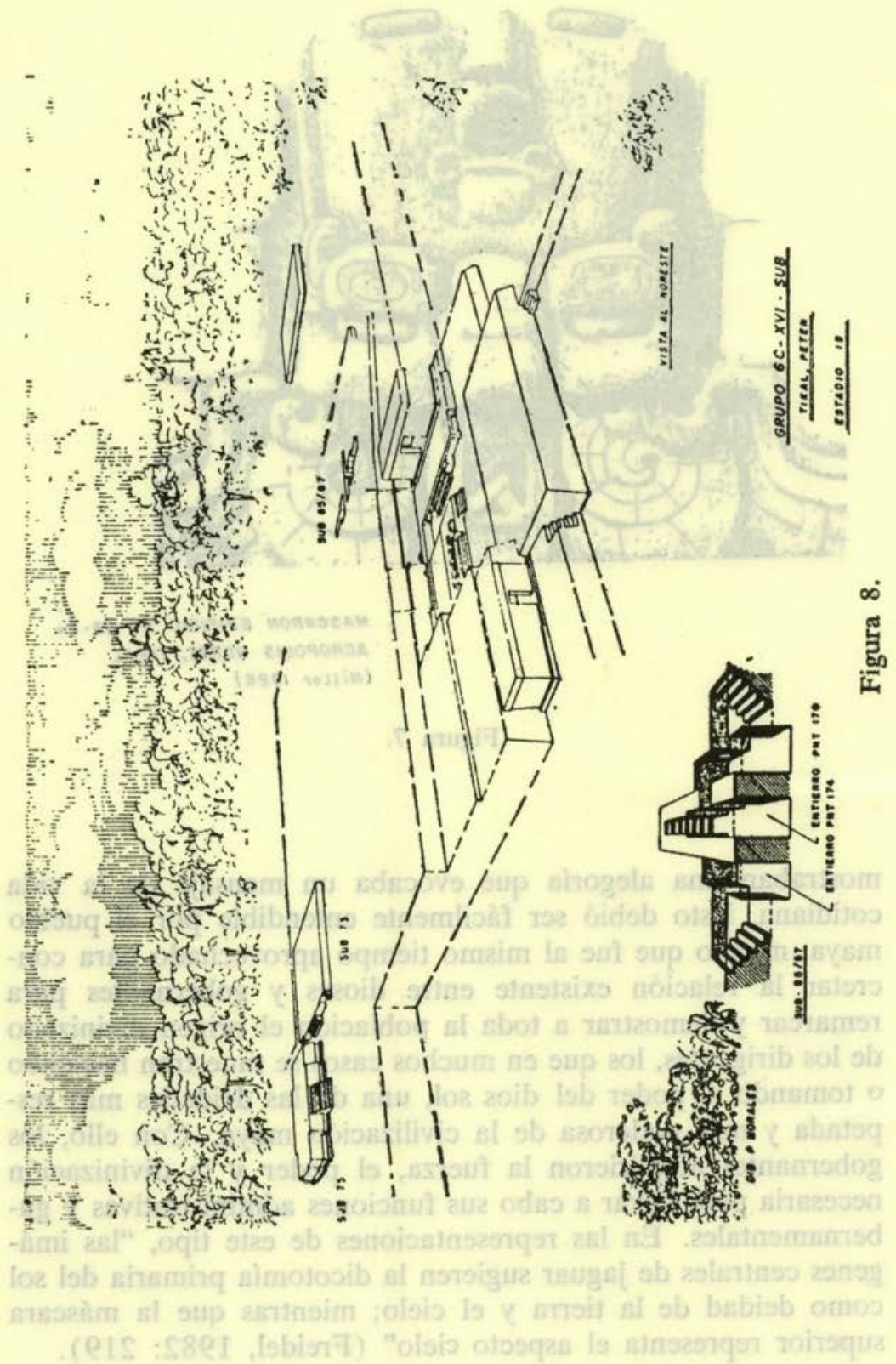


Mascarones ManiK 3-B (488-500 d-C.)

Para la parte inicial de Manik 3-B, alrededor del año 488 d.C., en el Grupo 6C-XVI fueron realizadas una serie de modificaciones arquitectónicas que vinieron a anular completamente los mascarones que estuvieron presentes en la plataforma Sub-4 de época anterior. Para Manik 3-B, este grupo fue ampliado hacia el norte con la construcción de varias estructuras, iniciándose el proceso con la edificación de Sub-73 y seguido posteriormente por Sub-75, presentando ambas la presencia de figuras decorativas en estuco (fig. 8).

\section{Edificio Sub-73}

La plataforma Sub-73, construida durante el estadio 18 y fechada para Manik 3-B, es una plataforma semicuadrada de solamente $85 \mathrm{~cm}$ de alto. Su fachada principal está orientada hacia el oeste, en donde presenta tres escalinatas, siendo la del centro la principal. El extremo sur de la fachada se encontró bastante mutilado, mientras que la sección norte apareció en buen estado de conservación. Junto al lado norte de la escalinata central, flanqueando este elemento funcional, fue descubierto un mascarón con restos de pintura roja, el cual mide $3.70 \mathrm{~m}$ de largo, $85 \mathrm{~cm}$ de alto y está por un cuadro de $15 \mathrm{~cm}$ de ancho (Valdés, 1983: 196-198).

Este mascarón (fig. 9) lleva grandes ojos redondos, labios prominentes y la boca abierta, de donde salen volutas hacia los extremos, así como incisivos que siguen la forma de la boca en su interior. Asimismo, porta a los lados el complejo de orejeras que es característico en este tipo de representaciones endiosadas. Esta figura orientada hacia el oeste, lugar de la puesta del sol, es clara representación de un jaguar relacionado con la deidad solar del inframundo, y aunque con sus propias particularidades, guarda similitud con los mascarones preclásicos encontrados sobre el edificio H-Sub-3 de la plaza sur del Grupo H en Uaxactún (Valdés, 1987a; 1987b).

Diversos autores han observado que tanto en los altiplanos mexicanos como en la zona maya, el jaguar representa la noche y la oscuridad, además que existe una dualidad con el dios sol. De ahí la importancia que esta representación se encuentre 


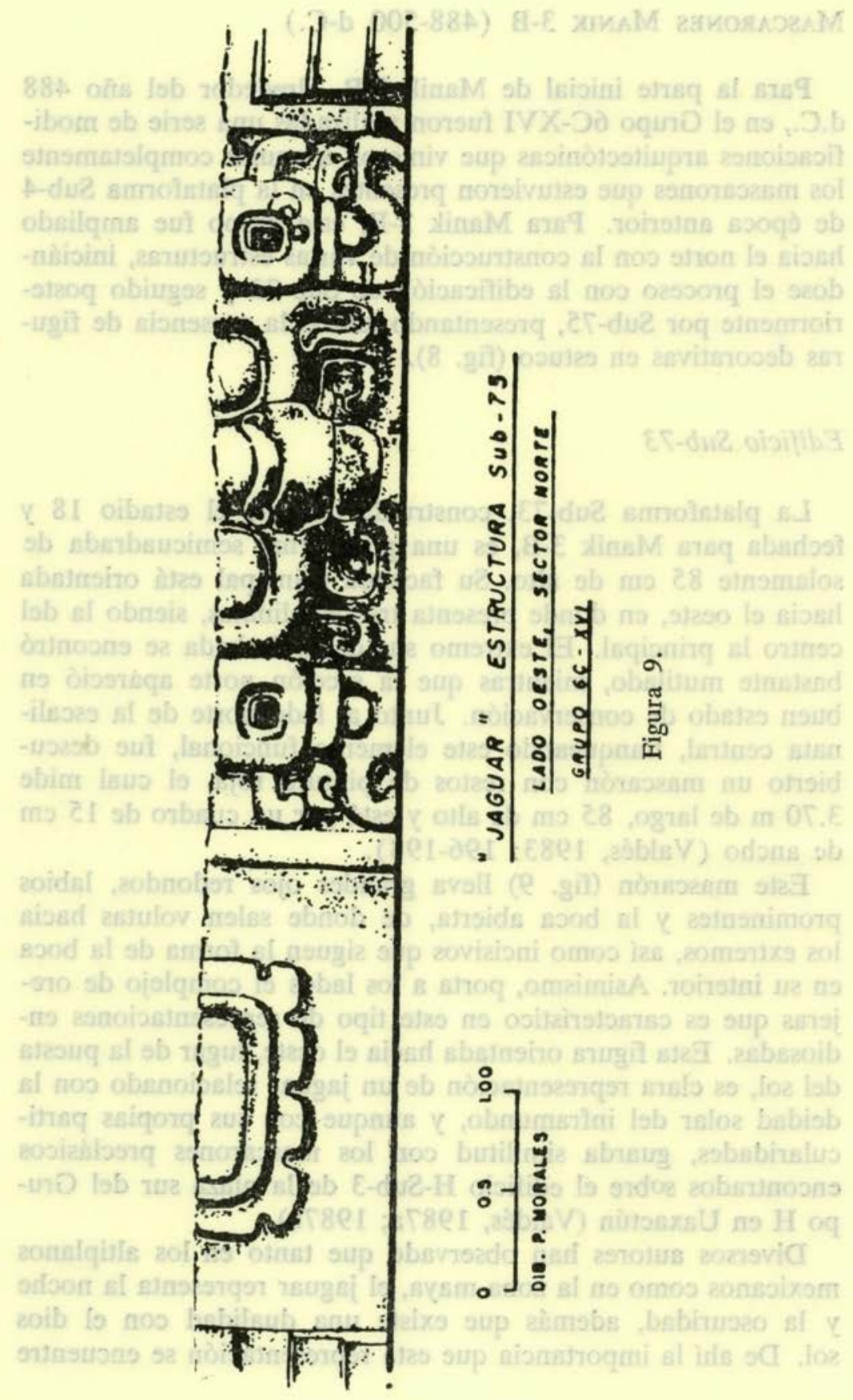


orientada hacia el oeste. Al respecto de la importancia del jaguar en la ideología prehispánica, Thompson (1977: 355) anota: "Baste decir que el jaguar está íntimamente ligado al mundo inferior, región de las sombras y al cielo nocturno. Por ello se convierte en un nuevo caso de dualidad, porque reina en el cielo y en la tierra o bajo de ella. La creencia lacandona que el mundo lo acabarán los jaguares que subirán del inframundo para devorar el sol y la luna, ilustra perfecamente la interrelación entre el cielo y tierra".

\section{Edificio Sub-75}

Unos años más tarde de que fuera construida la plataforma Sub-73, se decidió realizar la edificación de la plataforma Sub75 inmediatamente al oeste, la cual tiene dimensiones de $14.10 \mathrm{~m}$ norte-sur, $14.50 \mathrm{~m}$ este-oeste y una altura máxima de $1.85 \mathrm{~m}$ (figs. 8 y 10 ).

La plataforma Sub-75 presenta una característica particular ya que es de los pocos edificios conocidos en el área Maya que se encuentran decorados con mascarones estucados en sus cuatro lados, caso similar al que ocurrió en la pirámide E-VII-Sub de Uaxactún durante el Preclásico Tardío.

En la plataforma Sub-75 fueron descubiertos cuatro mascarones en el llado norte y cuatro al este, mientras que al oeste solamente se descubrieron dos, debido a que los del resto fueron mutilados. El sector sur se encontró destruido parcialmente, pero se considera también la presencia de cuatro mascarones flanqueando la única escalinata de acceso a la parte superior de la plataforma. En total, este edificio contó con un número de 16 mascarones (cuatro de cada lado), construidos con piedra de talla mediana en su sector central, mientras que piedra pequeña fue utilizada para formar elementos como nariz y orejas, estando todos cubiertos con estuco de color rojo (Valdés, 1983: 134-139).

Para este momento (Manik 3B), se abandonó en el Grupo $6 \mathrm{C}-\mathrm{XVI}$ el uso de representaciones con dominio zoomorfo, convirtiéndose en figuras predominantemente antropomorfas, como el caso de la plataforma Sub-75 (fig. 10 y 11). Aquí se observan las cabezas humanas con nariz pronunciada y boca abierta, llevando todos un tocado sobre la cabeza, orejeras circulares 


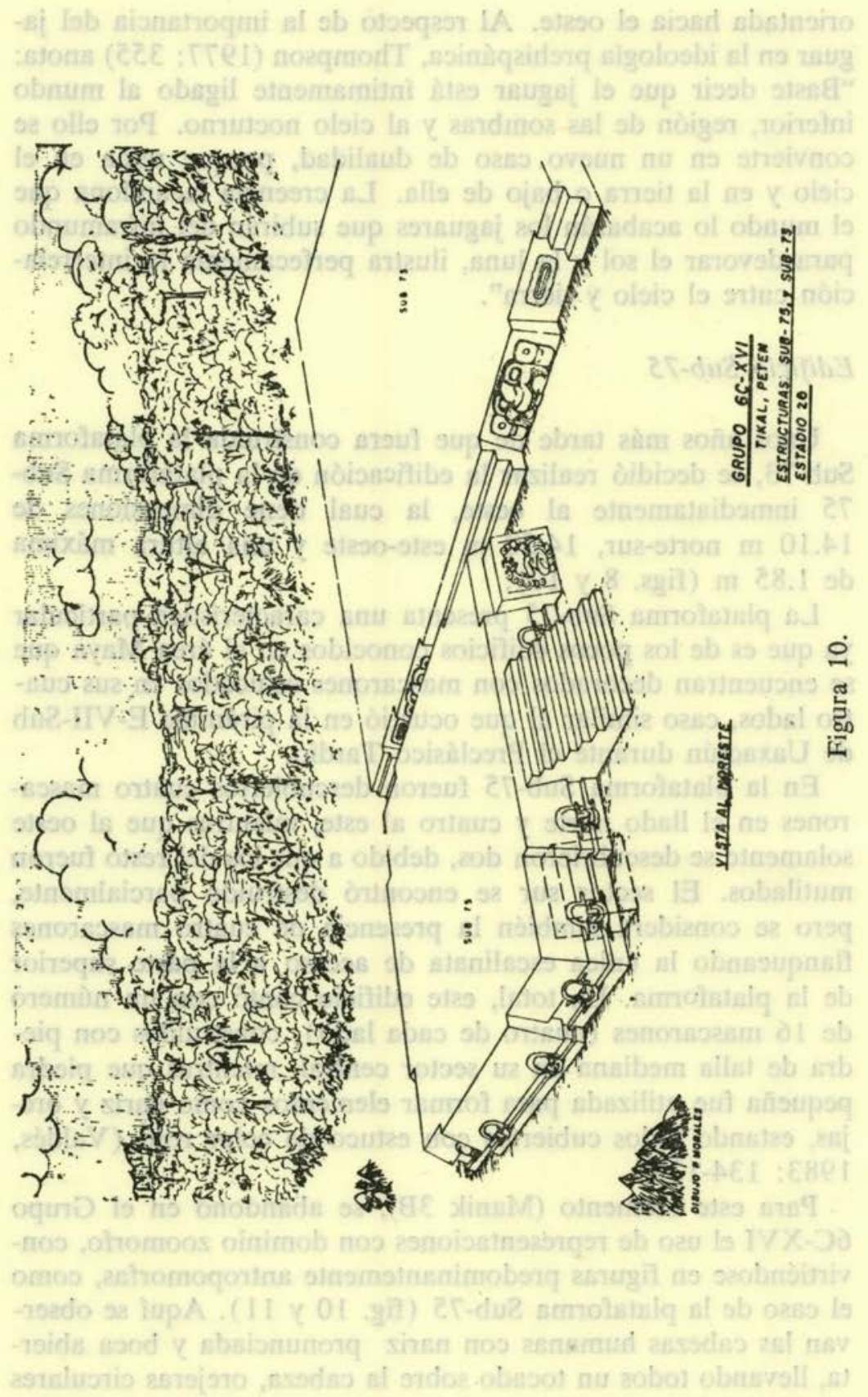




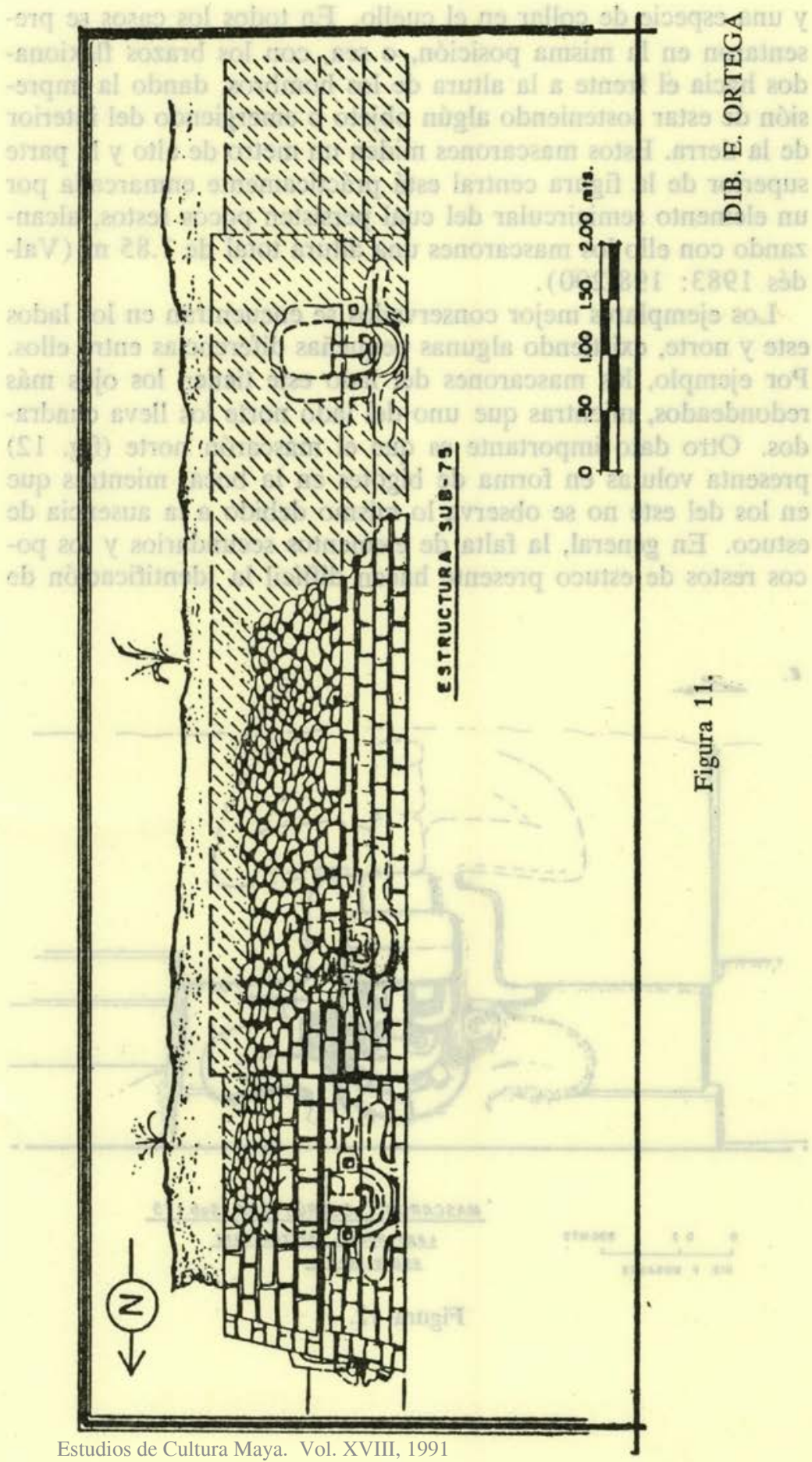

Instituto de Investigaciones Filológicas/

Centro de Estudios Mayas, UNAM 
y una especie de collar en el cuello. En todos los casos se presentaron en la misma posición, o sea, con los brazos flexionados hacia el frente a la altura de los hombros, dando la impresión de estar sosteniendo algún objeto o emergiendo del interior de la tierra. Estos mascarones miden un metro de alto y la parte superior de la figura central está prácticamente enmarcada por un elemento semicircular del cual persisten pocos restos, alcanzando con ello los mascarones una altura total de $1.85 \mathrm{~m}$ (Valdés 1983: 198-200).

Los ejemplares mejor conservados se encuentran en los lados este y norte, existiendo algunas pequeñas diferencias entre ellos. Por ejemplo, los mascarones del lado este tienen los ojos más redondeados, mientras que uno del lado norte los lleva cuadrados. Otro dato importante es que el mascarón norte (fig. 12) presenta volutas en forma de bigotes en la boca, mientras que en los del este no se observa lo mismo debido a la ausencia de estuco. En general, la falta de elementos secundarios y los pocos restos de estuco presente hacen diflícil la identificación de

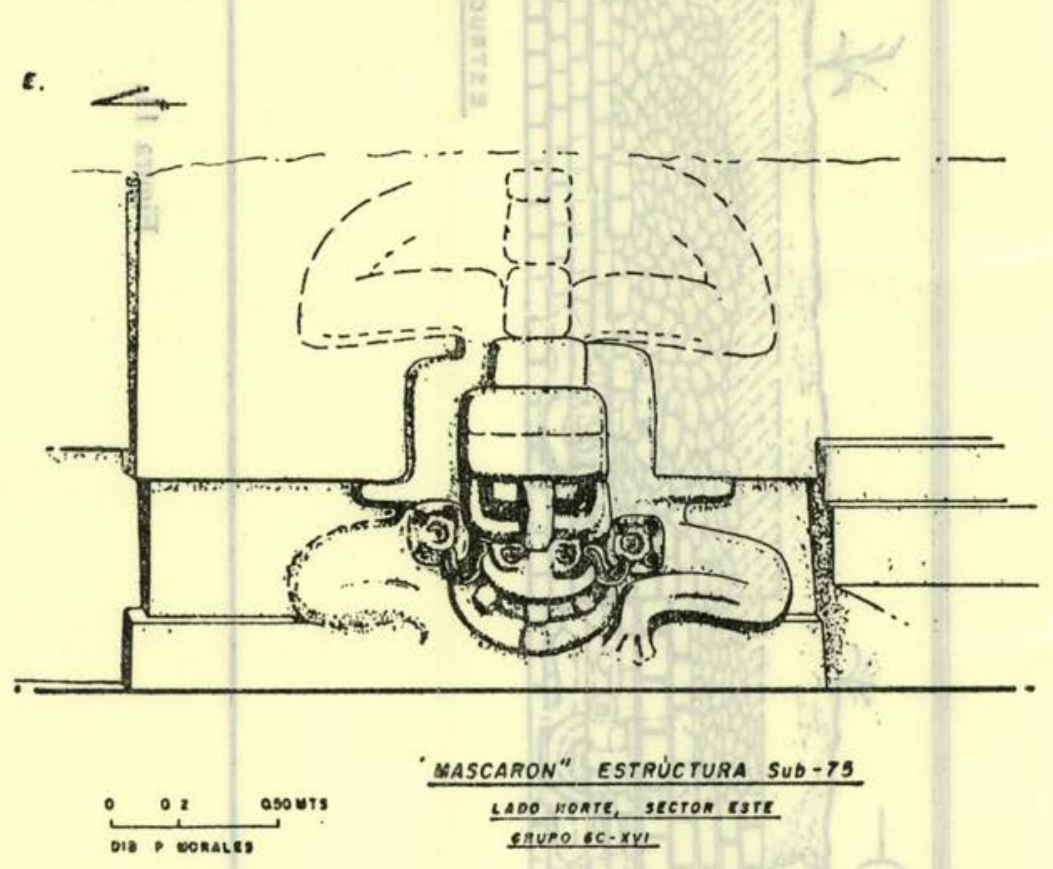

Figura 12. 
estos mascarones. Sin embargo, el rasgo común en todos los ejemplares presentes es la postura encorvada.

Dos ejemplares del Clásico Temprano, que guardan similitud con los mascarones de la estructura Sub-75, pueden verse en la sección superior del edificio 5D-33-2o. en la Acrópolis del norte de Tikal (fig. 13). Aunque se les ha asignado una relación con Venus como lucero del alba (Miller, 1986: 46), es importante notar la similitud existente en la posición encorvada o agachada que se demuestra por la posición de los brazos. Por otro lado, en el sitio de Santa Rita en Belice (fig. 14), se en-

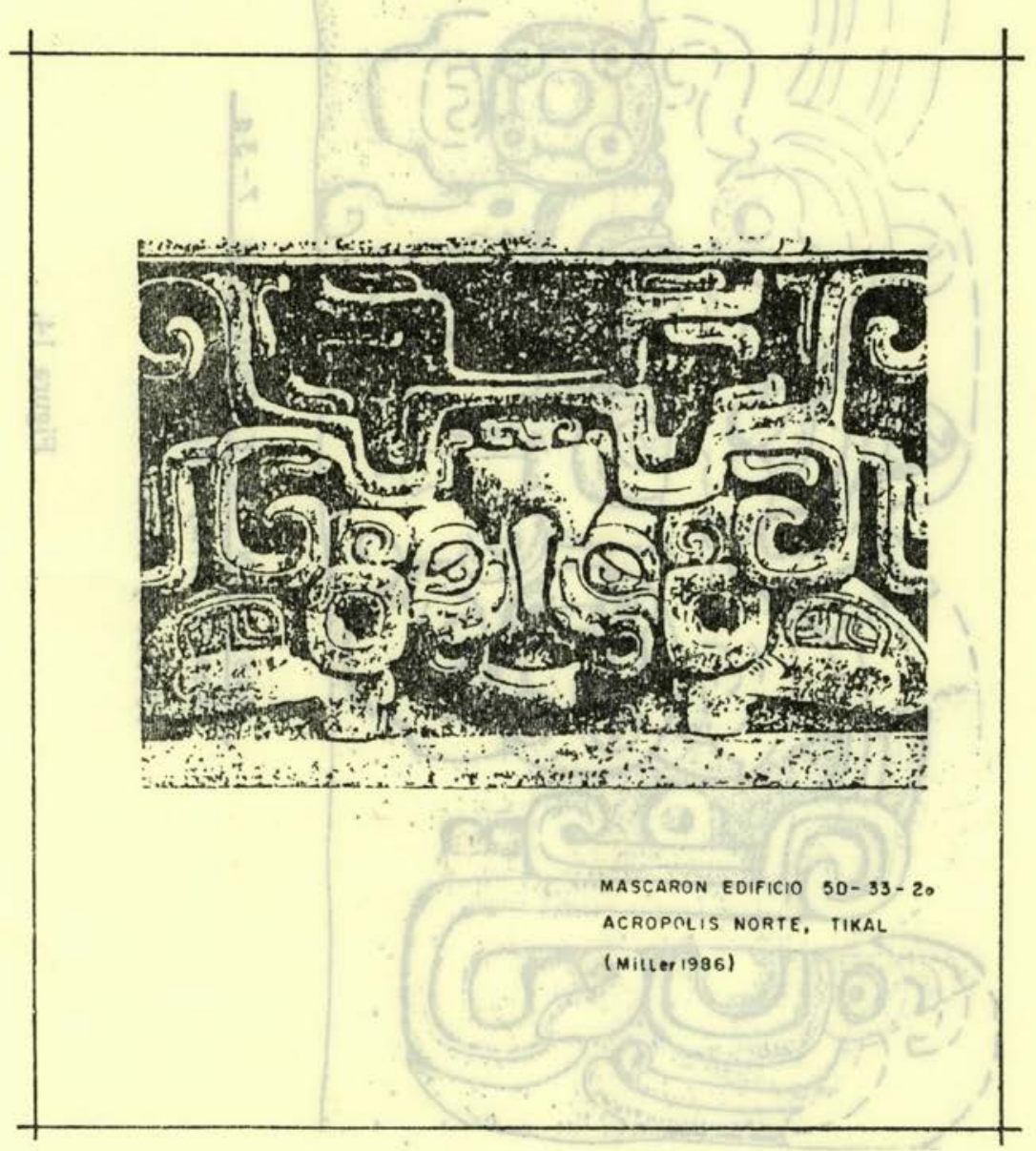

Figura 13. 


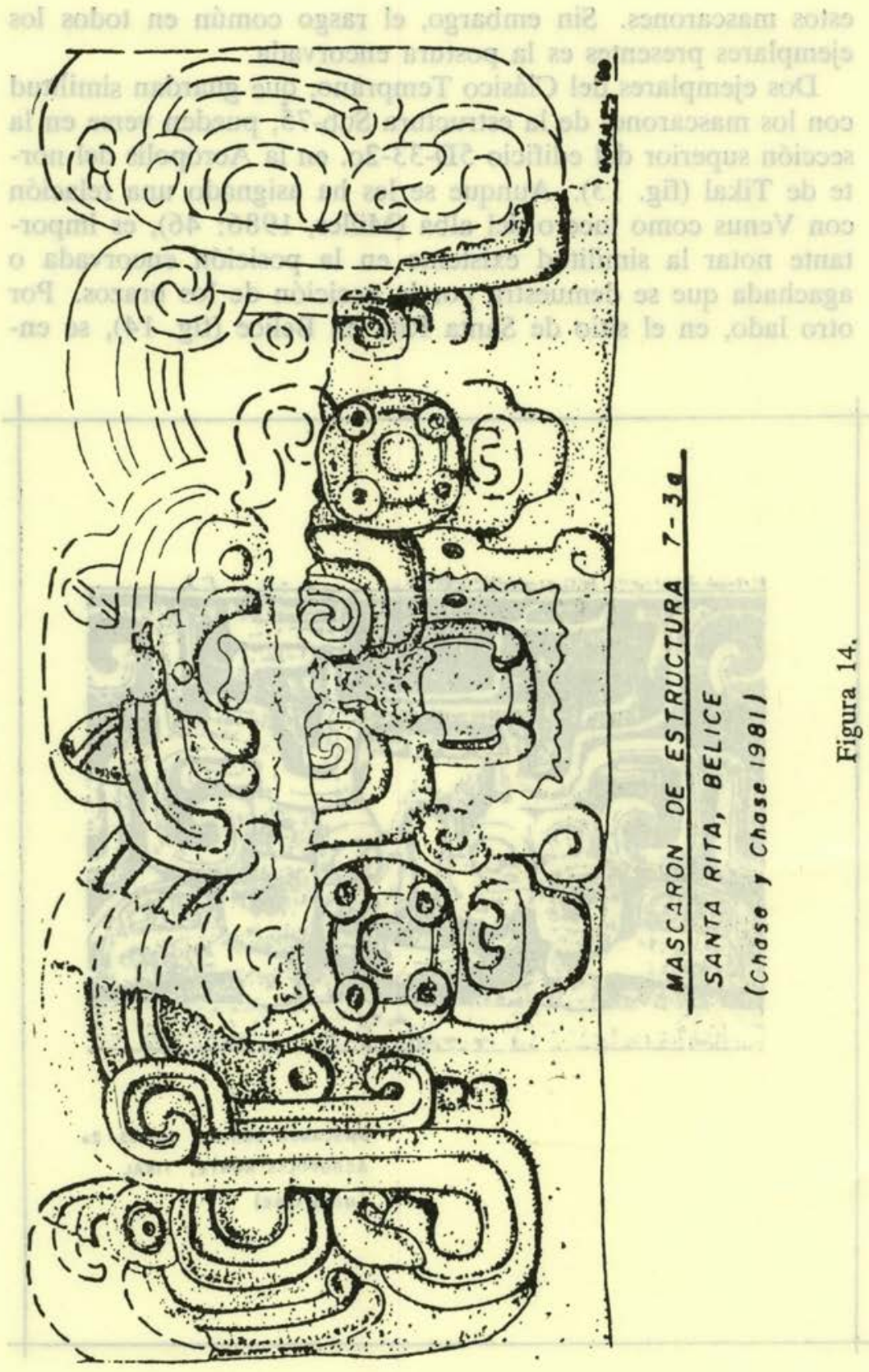


contró un mascarón sobre la estructura 7-3a. que mide cerca de un metro de alto, y aunque difiere con los de la estructura Sub-75 por la ausencia de brazos y por contar con una serie de elementos secundarios, es notoria la semejanza en la parte central de las figuras. El mascarón de Santa Rita ha sido fechado para el Clásico Medio (Chase y Chase, 1981: 43-44), y corresponde en temporalidad con los mostrados en la estructura Sub-75 del Grupo 6C-XVI de Tikal.

En los ejemplares de Santa Rita y la Acrópolis del Norte se nota asociación con fenómenos estelares, como lo son el sol y Venus. Podría considerarse, por lo tanto, que los ejemplares representados en el Grupo 6C-XVI puedan ser una mezcla de imágenes naciendo en el mundo inferior, pero con atributos de deidades del mundo superior, como podría ser el sol naciente y debido a ello la presencia de volutas en forma de bigotes sobre el mascarón mejor conservado del sector norte. Sin embargo, la postura encorvada también los hace semejarse al dios $\mathrm{N}$, y por otra parte también podría pensarse en Bacabs, tanto por su postura como por ser cuatro mascarones en cada uno de los lados.

Los continuos cambios y remodelaciones arquitectónicas frecuentes de encontrar en las tierras bajas, afectaron también el lado sur de la plataforma Sub-75 que hemos venido mencionando. En este sector fueron cubiertos los mascarones anteriores colocándoseles enfrente una especie de bloques que presentan otras figuras estucadas y que flanquean la escalinata de acceso a la parte superior del edificio (fig. 10). Unicamente se conserva una de estas figuras (lado este) que forma un panel de un metro de alto, 1.48 de ancho y está bordeada por marcos laterales de $23 \mathrm{~cm}$; está esculpido en piedra y recubierto de estuco pintado de color rojo (fig. 15). Aquí está mostrado un personaje en posición sedente con las piernas cruzadas, es de cuerpo entero y la cara se encuentra destruida. La orientación de las piernas es hacia el oeste, pero el tórax y la cara presentan un movimiento dinámico bien dado por el artista ejecutor de la obra, haciendo que estas partes se orientaran hacia el sur. Lleva desnudo el torso, piernas y pies, pero presenta una faldilla con un cinturón ricamente esculpido que pende de su lado izquierdo, así como también orejeras, collar, brazaletes y una 


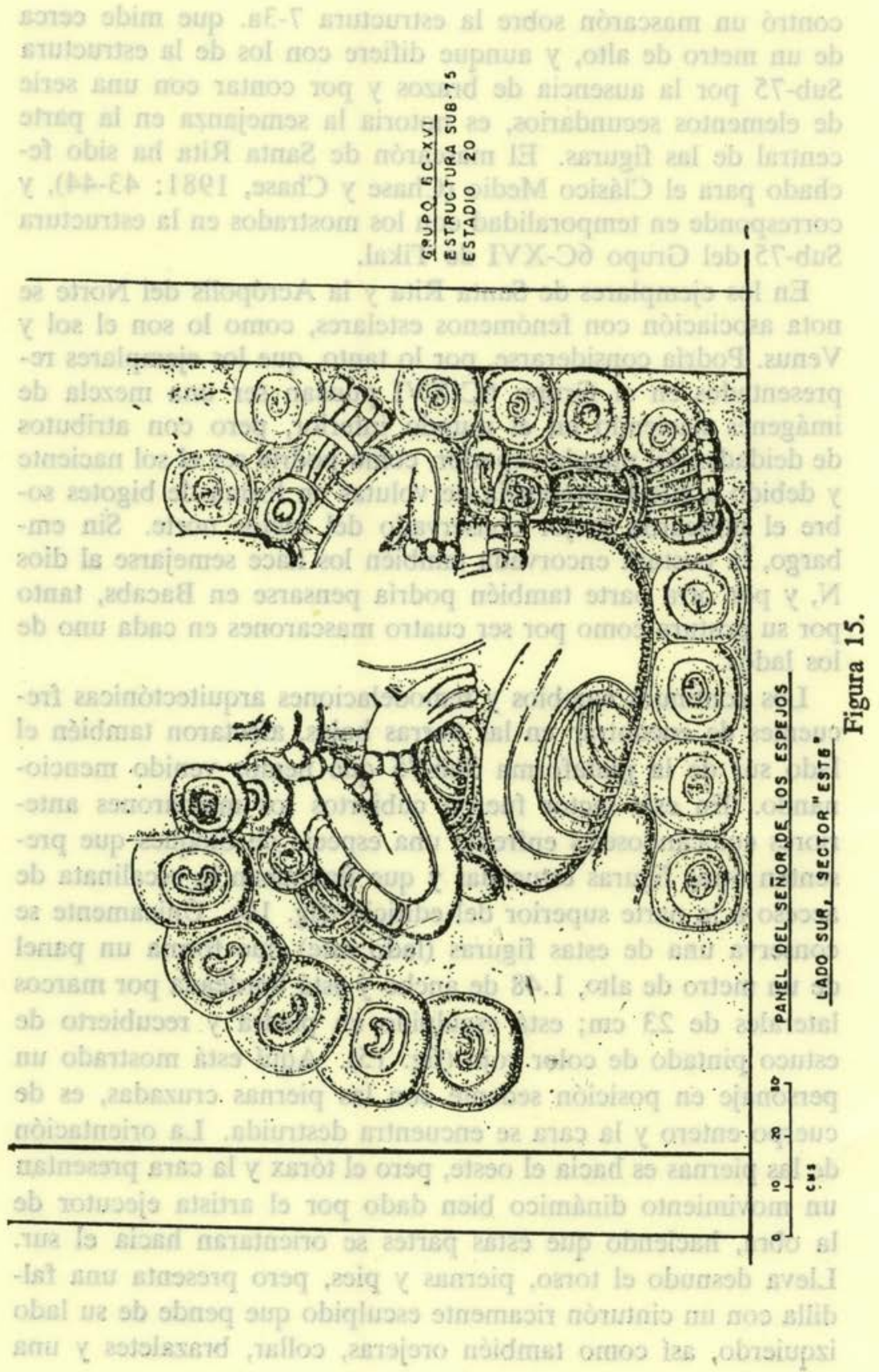


especie de trenzas que forman parte del tocado que desciende de la cabeza (Valdés, 1983: 141-147, 200-204).

Uno de los brazos reposa sobre un glifo, que aparece también sobre la pierna izquierda, y que ha sido identificado como el glifo espejo o Nen (T617a). Este glifo aparece comúnmente presente en relación con el dios $\mathrm{K}$, y en los textos de Palenque se encuentra en los tocados de divinidades como marca de dios, por lo que puede verse en este glifo el proceso de sucesión real así como la defensa mitológica del poder (Robicsek, 1978: 104107). Según Schele y Miller (1986: 43), en el caso de figuras antropomorfas, el glifo espejo es un indicador especial que aparece sobre brazos, piernas y torsos indicando su estatus como dioses. Asimismo, los personajes históricos que han muerto y que pasan a formar parte del reino sobrenatural también portan el glifo espejo como marcador de su alto estatus y categoría divina.

En el caso del personaje sedente de Sub-75 en discusión, el aspecto sobrenatural está apoyado por la presencia de pequeños círculos incisos que rodean la escena, los que en algunos casos presentan círculos en su interior, mientras que en otros tienen una especie de media luna en el centro. Estas formas incisas han sido identificadas como conchas seccionadas y completas, que aparecen también sobre el cinturón y cerca de la cabeza. Thompson (1978: 278-280) relaciona las conchas con el símbolo del agua, el señor de la noche o del inframundo y como uno de los elementos que indican el lado sur en la mitología maya. Esto hace, por lo tanto, que el personaje sedente sea interpretado como un importante personaje que fue esculpido aquí después de su muerte, el cual debió formar parte del linaje de Título Ma'Chuch de Tikal y que fueron los pobladores del Grupo 6C-XVI. Con anterioridad se ha indicado (Laporte y Fialko, 1987) que este linaje gobernó en Tikal durante varias generaciones a partir del año 378 d.C., lo cual nos lleva a considerar la posibilidad que el personaje esculpido en el edificio Sub-75 haya desempeñado funciones de primer orden o que-conllevaron la consolidación de este linaje en Tikal, por lo que prácticamente adquirió el derecho a ser recordado y divinizado por los miembros de su grupo, si no de un número mayor de personas. 

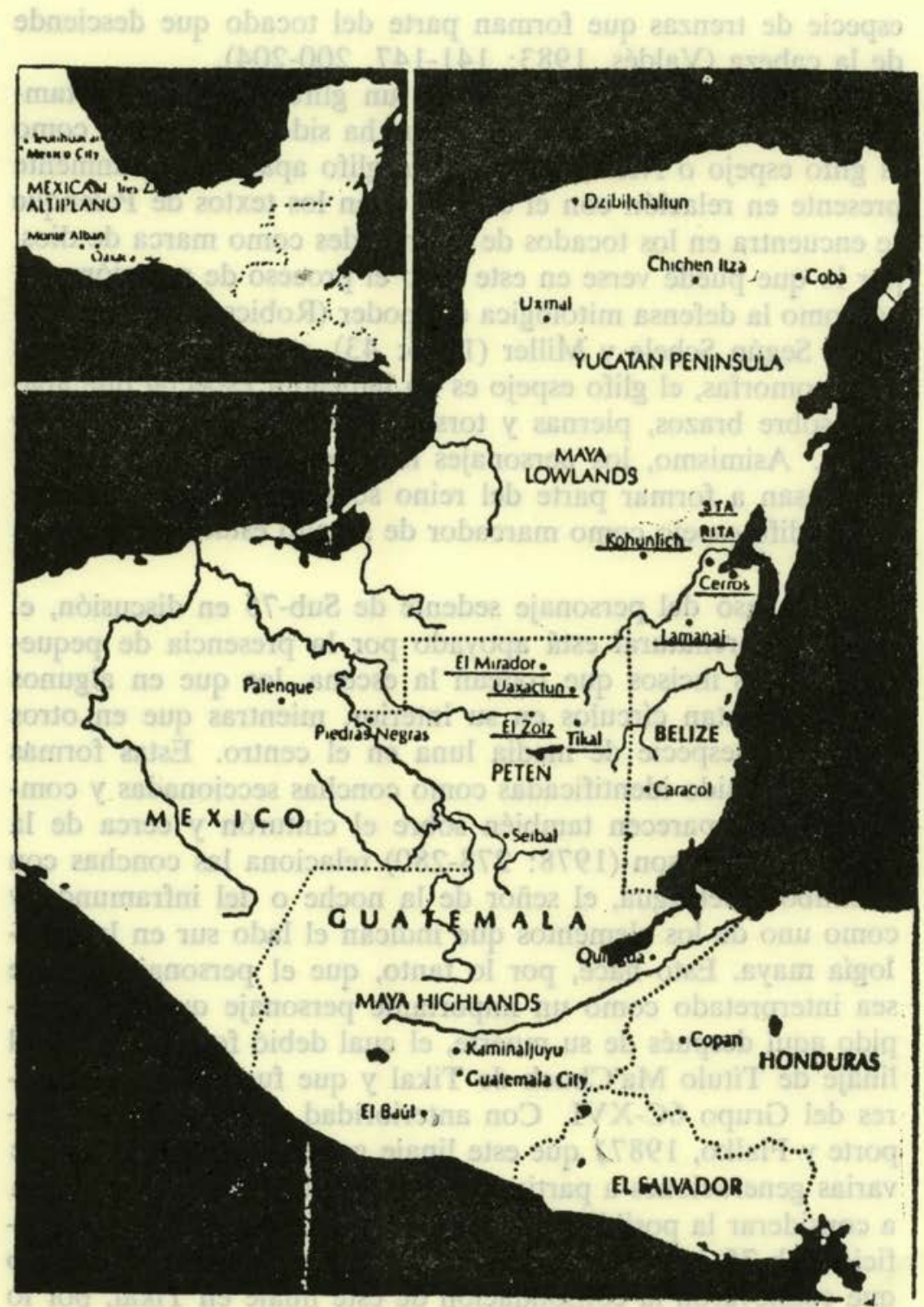

AREA MAYA

SITIOS CON MASCARONES

Figura 16. 


\section{Discusión}

Como sabemos, las muestras iconográficas que relacionan escultura con arquitectura fueron ampliamente representadas durante el Preclásico Tardío en sitios como Tikal, Uaxactún, Mirador, Cerros y Lamanai (Valdés, 1987a), rasgos que continuaron siendo utilizados durante el periodo Clásico expandiéndose hacia otros sectores de la región maya como Kohunlich y Santa Rita, así como también posiblemente en los mascarones no fechados aún del sitio El Zotz (fig. 16).

Las complejas figuras preclásicas están íntimamente ligadas con motivos sobrenaturales, en donde el dios solar en sus diversos aspectos tomó el papel preponderante, expresando sus pasos por el mundo celeste y el inframundo. Durante el Clásico Temprano, la utilización de monumentos esculpidos como altares, estelas y posteriormente dinteles de madera que muestran personajes y escritura jeroglífica, vino a sustituir en cierta forma las complejas muestras iconográficas de autoridad preclásicas. Los cambios sociopolíticos que dieron inicio al periodo Clásico se reflejan también en los mascarones asociados a la arquitectura del momento, principiando a desaparecer la utilización de complejos motivos sobrenaturales, para dar paso a una nueva forma y estilo en el uso de las grandes máscaras, en donde vino a generalizarse el proceso de divinización de los gobernantes como elemento central de la figura.

Aunque en algunos sitios este cambio es más notorio, tal y como se puede observar en los mascarones de Lamanai y Kohunlich (fig. 17) en donde se muestra el proceso de engrandecimiento y divinización de los gobernantes que se convierten en el sujeto central de las figuras, en otros sitios el cambio parece haber sido más lento o mezclando aún las reminiscencias del pasado con el surgimiento de las nuevas formas e ideas, tal es el caso de Tikal, en donde alglunos edificios del periodo Clásico presentan complicadas muestras iconográficas mientras que otros principian a utilizar iconografía más simple, lo cual es notorio en los edificios que componen la Acrópolis del Norte.

En el caso de los mascarones del Grupo 6C-XVI puede verse que la temática está orientada hacia diferentes puntos, pero en todo momento guarda una fuerte relación que liga lo natural con los elementos sobrenaturales. La metáfora mejor utili- 


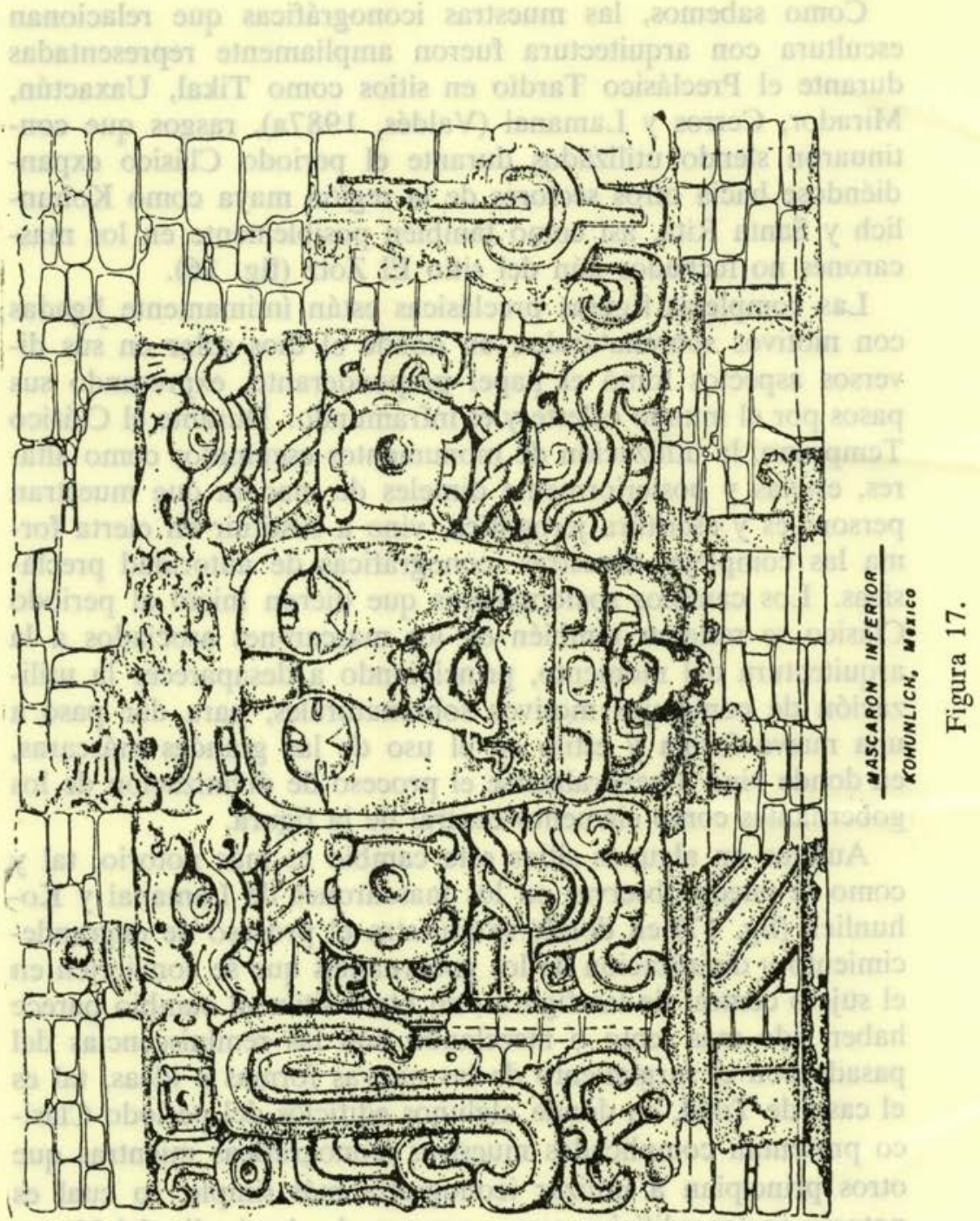


zada en los mascarones de la parte media del Clásico Temprano (Manik 2) en el edificio Sub-4 está enfocada a la figura del sol como la máxima divinidad y la fuerza superior del firmamento, que genera su poder a una figura antropomorfa que también podría ser un importante personaje local, mostrándose con ello la tradición preclásica del sol naciente. Durante la parte final del Clásico Temprano (Manik 3-B), las muestras iconográficas del edificio Sub-75 denotan una preferencia en la representación de seres antropomorfos, desapareciendo por completo el uso de las volutas en la escena.

Debe considerarse que los gobernantes que lograron constituir los señoríos o estados tempranos durante el Preclásico Tardío vinieron a ser vistos como el sol de su pueblo, o sea el creador de la vida y protector del crecimiento de ese pueblo. Debido a ello, también en el Clásico Temprano los gobernantes fueron vistos como equiparados al itinerario del astro solar, la majestad y vigor también fue comparable entre gobernantes y el sol, irradiando ambos la energía necesaria para la continuación de la vida. En la mentalidad maya "cuando el rey muera bajará al inframundo del mismo modo que lo hace en el crepúsculo diario el sol, y luego de una violenta lucha con las potencias tenebrosas, renacerá el sol, igual que sucede con los héroes Hunahpú e Ixbalanqué en el poema mitológico de los quichés" (Rivera Dorado, 1986: 149).

Por esto mismo, encontramos durante todos los periodos de la civilización maya una estrecha vinculación entre el sol y los gobernantes, y aunque a partir del periodo Clásico los gobernantes llegaron a ocupar el primer lugar de las escenas como elementos centrales, éstos siempre aparecerán acompañados de símbolos solares o estelares como muestra de su gran fuerza y del poder para controlar los acontecimientos que rigieron la vida de un pueblo.

\section{BiBLIOGRAFÍA}

Becker, Marshall Joseph

1982 Ancient Maya Houses and their identification: An evaluation of architectural groups at Tikal and inferences regarding their functions.

Revista Española de Antropología Americana, vol. XII, pp. 111-129, Madrid, España. 
CARR, R. F. Y J.E. HAZARD

1961 Map of the Ruins of Tikal, El Petén, Guatemala. Tikal Report, No. 11, Museum Monographs, University Museum Philadelphia.

Chase, Arlen y Diane Chase

1981 Archaeological Investigations at Nohmul and Santa Rita, Belize: 1979-1980.

Coe, William

Mexicon, vol. II, No. 3, pp. 42-44, Berlín, Alemania.

1965 Tikal, Guatemala, and emergent Maya Civilization. Science, vol. 147 , No. 3664 , pp. 1401-1419.

FialKo, Vilma

1987 El marcador de Juego de Pelota de Tikal: Nuevas evidencias epigráficas para el Clásico Temprano.

Memorias del 1er. Simposio Mundial de Epigrafía Ma$y a$, pp. 61-80, Guatemala.

FREIDEL, DAVID

1982 Civilization as a State of Mind: The Cultural Evolution of the Lowland Maya.

The Transition to Statehood in the New World, Cambridge University Press, pp. 188-227, Cambridge.

1985 Polychrome facades of the Lowland Maya Preclassic. Painted Architecture and Polychrome Monumental

Sculpture in Mesoamerica, Edif. E. Boone, pp. 5-30, Dumbarton Oaks, Washington, D.C.

HANSEN, RichaRd

1984 Excavations on Structure 34 and The Tigre Area, El Mirador, Petén, Guatemala: A New Look at the Preclassic Lowland Maya.

Tesis de Maestría, Universidad de Brigham Young.

LAPORTe, JuAn Pedro

1985 Arquitectura Clásica Temprana de Tikal y el Modo Talud-Tablero.

Antropología e Historia de Guatemala, vol. VII, pp. 1-48, IDAEH, Guatemala.

1987 El Grupo 6C-XVI, Tikal, Petén: Un centro habitacional del Clásico Temprano.

Memorias del I Coloquio Internacional de Mayistas, Centro de Estudios Mayas, pp. 221-244, UNAM, México.

Laporte, Juan Pedro y Vilma Fialko (Eds.)

1985 Reporte Arqueológico del Mundo Perdido y zonas de habitación Tikal, Petén.

10 vol. IDAEH, Guatemala. 
1987 Nuevas referencias para viejos problemas: Enfoques dinásticos sobre el Clásico Temprano en Tikal.

Ponencia presentada en "Vision and Revision in Maya Studies", Albuquerque, Nuevo México.

Matheny, Ray

1987 An Early Maya Metropolis Uncovered: El Mirador. National Geographic, vol. 172, No. 3, pp. 317-339, Washington.

Miller, Arthur

1986 Maya Rulers of Time.

The University Museum, Universidad de Pensylvania.

Pendergast, David

1981 The 1980 Excavations at Lamanai, Belize.

Mexicon, vol. II, No. 6, pp. 96-99, Berlín, Alemania.

Rivera Dorado, Miguel

1986 Cambios en la religión Maya, desde el periodo Clásico a los tiempos de Hernán Cortés.

Los Mayas de los Tiempos Tardios, ed. M. Rivera y

ROBICSEK, FRANCIS

A. Ciudad, pp. 147-165, Madrid, España.

1978 The Smoking Gods: Tabacco in Maya Art History and Religion.

Universidad de Oklahoma.

Schele, Linda y M. E. Miller

1986 The Blood of Kings.

Kimbell Art Museum, Forth Worth.

THOMPSON, ERIC

1977 Historia y Religión de los Mayas.

Edit. Siglo XXI, 2a. ed., México.

1978 Maya Hiroglyphic Writing.

Universidad de Oklahoma.

Valdés, Juan Antonio

1983 Étude de groupes D'habitations du centre ceremonial Maya du "Mundo Perdido", Tikal, Guatemala.

Tesis doctoral, Universidad de la Sorbona, París, Francia.

1985 Investigación habitacional de los Cuadrantes Perdido y Corriental de Tikal: Una formulación.

Antropolgía e Historia de Guatemala, vol. VII, pp. 49-65, IDAEH, Guatemala.

1986 Uaxactún: Recientes Investigaciones.

Mexicon, vol. VIII, No. 6, pp. 125-128, Berlín, Alemania. 
1987a. Los Mascarones Preclásicos de Uaxactún: El caso del Grupo H.

Memorias del 1er. Simposio Mundial de Epigrafía Ma$y a$, pp. 165-181, Asociación Tikal, Guatemala. (1986).

1987b. El Grupo H de Uaxactún: Evidencias de un centro de poder durante el Preclásico.

Ponencia presentada en el II Coloquio Internacional de Mayistas, Campeche, México. 